\title{
Peers at Work: Economic Real-Effort Experiments in the Presence of Virtual Co-Workers
}

Andrea Bönsch ${ }^{1,2}$, Jonathan Wendt ${ }^{1,2}$, Heiko Overath ${ }^{1,2}$, Özgür Gürerk ${ }^{3}$, Christine Harbring ${ }^{3}$, Christian Grund $^{3}$, Thomas Kittsteiner ${ }^{3}$, Torsten W. Kuhlen ${ }^{1,2}$

${ }^{1}$ Visual Computing Institute, RWTH Aachen University, Germany $\quad$ 2JARA-HPC, Aachen, Germany

${ }^{3}$ RWTH School of Business \& Economics, RWTH Aachen University, Germany

\section{Introduction}

- Experimental Economics uses controlled and incentivized field and lab experiments to analyze economic behavior.

- General challenges researchers face:

In the Field: lack of significant amount of experimental control

In the Lab: experiments are often perceived as sterile and abstract

- Challenges by investigating peer effects:

Reflection problem [2]: „Who is influencing whom?"

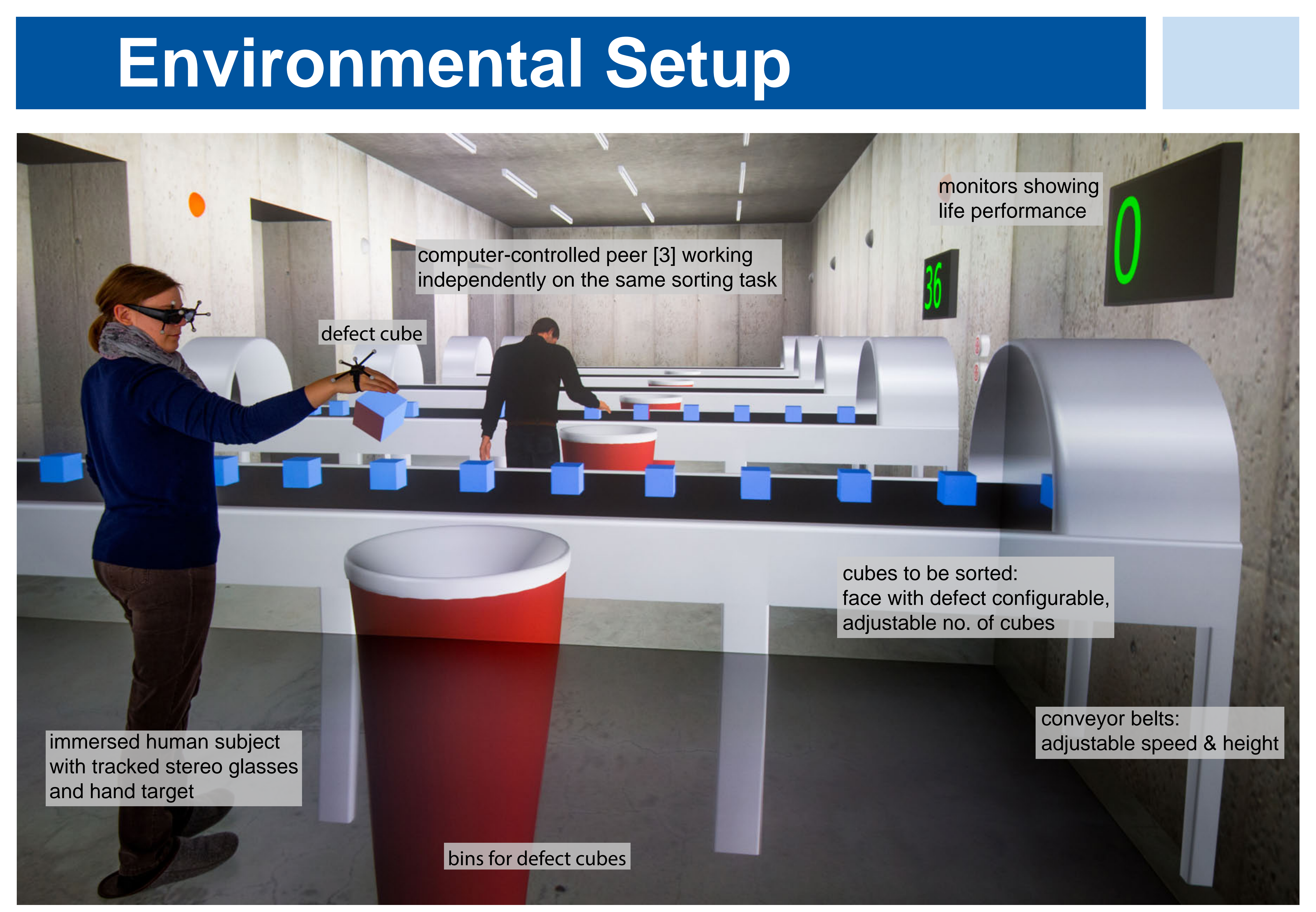

- Scenario to conduct real-effort, sorting tasks: subject physically grasps a cube for inspection. If one face has a different color, the cube is defect and has to be sorted out. - Apparatus: five-sided CAVE (no ceiling) with a size of $5.25 \mathrm{~m} \times 5.25 \mathrm{~m} \times 3.3 \mathrm{~m}(\mathrm{w} \times \mathrm{h} \times \mathrm{d}$ ) providing a $360^{\circ}$ horizontal field of regard.

\section{Study 2: Productivity Effects}

Research Focus Are there non-confounded peer effects, i.e., do subjects react accordingly to their peer's performance?

Agent's Behavior Predefined behavior: low and high productive agent

Treatments (Inbetween)

Two treatments after measurement of subject's individual ability: - Low productive agent performing same task

- High productive agent performing same task

\begin{tabular}{|c|c|c|}
\hline No. of Subjects & 108 & No. of Cubes \\
\hline
\end{tabular}

Results

- Results in line with predictions of social comparison theory: Stronger peer effect by high similarities between peer and fellow worker

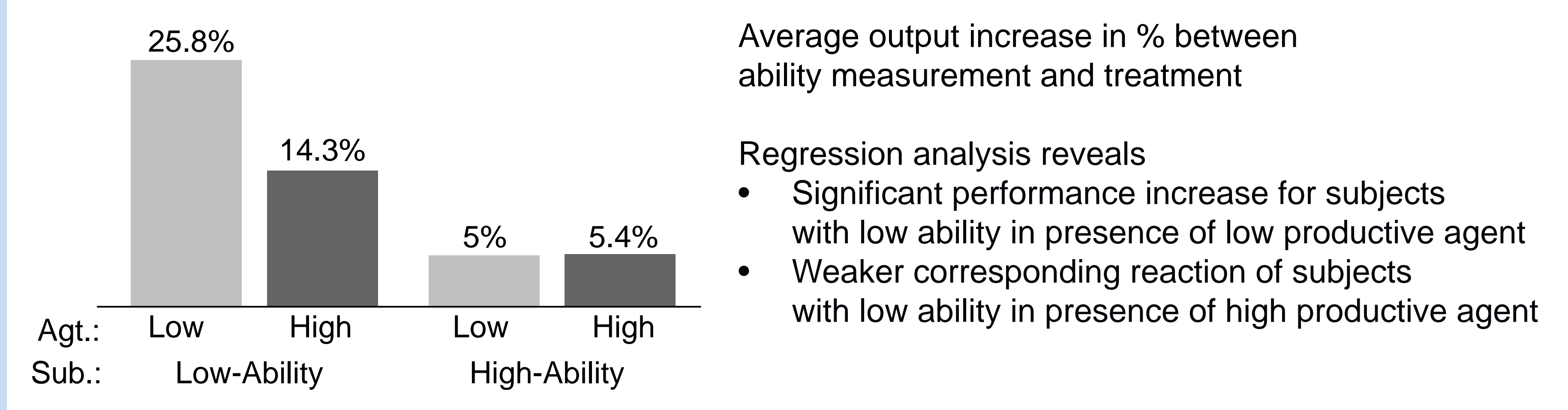

\section{Acknowledgements}

The depicted research was funded by RWTH Aachen University as Exploratory Research Space Seed Fund Project (2014/15), as PathFinder Project in the Research Area Managerial \& Organization Economics (2015/16), and by the project house ICT Foundations of a Digitized Industry, Economy, and Society (2016/2017).
We address the general issues by enlarging the methodological toolbox of these experiments by means of Virtual Reality as done in [1]

To overcome the reflection problem, we embed a computer-controlled, virtual agent as peer of the human subject.

\section{Study 1: Proof-of-Concept}

Research Focus Does additional monetary incentives induce a higher work effort in the subjects?

\section{Agent's Behavior No agent present.}

Treatments Four treatments after measurement of subject's individual ability: (Inbetween)

- Two fixed wage schemas: low, high

- Basic wage plus two piece rate schemas (low, high) per correctly sorted cube

\begin{tabular}{|c|c|c|c|}
\hline No. of Subjects & 120 & No. of Cubes & 360 (102 defect) \\
\hline \multirow{4}{*}{ Results } & \multicolumn{3}{|c|}{ - Results in line with well-known behavioral response patterns } \\
\hline & & $\begin{array}{l}\text { Average ou } \\
\text { ability meas }\end{array}$ & $\begin{array}{l}\text { ease in \% between } \\
\text { and treatment }\end{array}$ \\
\hline & & $\begin{array}{l}\text { Output defil } \\
\text { no. of d } \\
\text { no. of } 9\end{array}$ & $\begin{array}{l}\text { es sorted out minus } \\
\text { s sorted out falsely }\end{array}$ \\
\hline & & $\begin{array}{l}\text { Two-sided } \\
\text { output incre }\end{array}$ & $\begin{array}{l}\text { hitey } U \text { Test revealed a significan } \\
\text { csLo compared to FixLo and FixHii }\end{array}$ \\
\hline
\end{tabular}

Additional VR aspects:

- Subjects could perfectly deal with environment and task - No indicators that VR-experience distorted results

\section{Study 3: Competition}

Research Focus

Does competing against a peer elicit a higher performance in our subjects?

Agent's Behavior Endogenously: agent's performance adjusted to subject's ability based on first phase

Treatments (Inbetween)

Two treatments after measurement of subject's individual ability: - Piece rate per correctly sorted cube

- Pay based on relative performance compared to agent, who performs the same task (possibility to observe own and peer's current productivity at every time)

No. of Subjects $75 \quad$ No. of Cubes 360 (180 defect)

Results

- Competition elicited a higher performance than piece rates

- No decreasing performance with regard to last cubes in the competition treatment even for cases, in which the "winner" is fixed due to a large hitherto performance difference (subject is leading or lying behind with a large score difference)

\section{References}

[1] S. M. Fiore et al. Virtual Experiments and Environmental Policy. Journal of Environmental Economics and Management, 57(1):65 - 86, 2009.

[2] C. F. Manski. Identification of Endogenous Social Effects: The Reflection Problem. The Review of Economic Studies, 60(3):531-542, 1993.

[3] A. Shapiro. Building a Character Animation System. In J. Allbeck and P. Faloutsos, editors, Motion in Games, pp. 98-109, 2011. 